\title{
Atrazine derangement of GLUT-4 and Insulin metabolism and the ameliorative effect of Virgin coconut oil in male Wistar rats
}

\author{
Olatunbosun Titilope Helen ${ }^{1}$, Osim Eme Effiom ${ }^{2}$ Asuquo Etim Asuquo ${ }^{1}$, David Jessica Utibe ${ }^{1}$
}

\begin{abstract}
${ }^{1}$ Department of Physiology, Faculty of Basic Medical Sciences, University of Uyo, P.M.B. 1017, Uyo. Akwa Ibom State, Nigeria

${ }^{2}$ Department of Physiology, Faculty of Basic Medical Sciences, University of Calabar, Calabar, Cross Rivers State, Nigeria
\end{abstract}

\begin{abstract}
We assessed the ameliorative effect of Virgin Coconut Oil following atrazine-induced metabolic derangement in rats. Adult male Wistar rats weighing 180-200g were used; randomly separated into two major groups. Thirty-five rats in the test group were randomly divided into five subgroups of 7 rats per sub-group and treated thus: Sub-group (SG) 1, 2, and 3 received $10 \mathrm{ml} / \mathrm{kg}$ of distilled water, $10 \mathrm{ml} / \mathrm{kg}$ VCO, $123 \mathrm{mg} / \mathrm{kg}$ of Atrazine respectively, SG4 was diabetic control; SG 5 was the diabetic group treated with $10 \mathrm{ml} / \mathrm{kg}$ of $V C O$ for 2 weeks, after which the animals were sacrificed, and blood collected for analysis. 35 rats for the recovery group were divided into 5 subgroups of 7 rats per sub-group and treated; SG 1, 2, 3, 4 , and 5 received $10 \mathrm{ml} / \mathrm{kg}$ distilled water, $10 \mathrm{ml} / \mathrm{kg} \mathrm{VCO}, 123 \mathrm{mg} / \mathrm{kg}$ of ATZ, respectively. After 2 weeks, the animals were re-treated thus: SG 1,2,3,4 and 5 received $10 \mathrm{ml} / \mathrm{kg}$ of distilled water, $10 \mathrm{ml} / \mathrm{kg}$ of VCO, $123 \mathrm{mg} / \mathrm{kg}$ of ATZ, $10 \mathrm{ml} / \mathrm{kg} V C O$, and $10 \mathrm{ml} / \mathrm{kg}$ distilled water, respectively. After 2 weeks, the animals were also sacrificed, and blood was collected for analysis. ATZ reduced serum insulin and caused a reduced expression of GLUT4. VCO restored GLUT4 levels but did not significantly restore the insulin to normal levels.
\end{abstract}

KEYWORDS: GLUT-4; Insulin; Atrazine; Virgin Coconut Oil; Diabetes; Glucose

\section{INTRODUCTION}

$\mathrm{G}$ lucose transporters are a large family of structurally related transport proteins that affect the entry of glucose molecules into the cell [1]. Three types of glucose transporters have been identified: sodiumglucose-linked transporter or sodium-dependent glucose co-transporter (SGLUT), facilitated diffusion glucose transporters, or sodiumdependent glucose transporters (GLUTS) and SWEETs $[1,2]$. The GLUTs transport glucose across the plasma membrane by means of a facilitated diffusion mechanism [1]. GLUT4 is the primary insulin-responsive glucose transporter found in the heart, skeletal muscles, adipose tissues, and brain. It belongs to class II of the GLUTs family of glucose transporters
[1]. GLUT4 is a significant mediator of glucose removal from the circulation and a key regulator of the whole-body glucose homeostasis [3]. Expression and translocation (to tissue surface) of GLUT4 receptors are mainly regulated by insulin secretion. Contraction of skeletal and cardiac muscles also increases expression and translocation of GLUT4 expression (4). Reduced GLUT4 expression is notably associated with insulin resistance [5]. In its basal state, most of the GLUT4 is located within specialized vesicles. In response to insulin or contraction stimulation, most of the transporters are rapidly translocated to the plasma membrane, where they take up extracellular glucose into the cell and then are recycled and stored until new stimulation occurs [6].

There is an association between diabetes and

Carrespondence: Olatunbosun Titilope Helen, Department of Physiology, Faculty of Basic Medical Sciences, University of Uyo, P.M.B. 1017, Uyo. Akwa Ibom State, Nigeria. E-mail: expensivetiti@gmail.com

eISSN: 2523-6709

pISSN: 2523-6695

DOI: 10.31878/ijcrpp.2021.53.01
(C) Authors; 2021. (CC BY-NC-SA 4.0)

This is an Open Access article which permits unrestricted non-commercial use, provided the original work is properly cited. 
GLUT4 concentration and responsiveness. Mice with type II DM have been indicated to have up to $70 \%$ reduction of GLUT4 in the cardiac muscle [7]. Oxidative stress was reported to cause oxidation and carbonylation near the glucose transport channel of GLUT4 transporters, thus leaving them dysfunctional; this dysfunction results in insulin resistance [8]. So, there seem to exist a two-way relationship between GLUT4 and DM: reduced GLUT4 production/expression results in insulin resistance - although GLUT4 polymorphism is rare, and mutations are more likely to occur in the elderly [9], and the mechanism of insulin resistance may result in an impaired translocation and expression of GLUT4 at various sites [10]. Translocation of GLUT4 to the cell surface is a significant part of the underlying molecular mechanism responsible for the insulin-mediated increased Vmax of glucose transport [1]). Transgenic manipulation of GLUT4 levels has revealed that GLUT4 is, indeed, rate-limiting for insulindependent glucose uptake [12, 13].

Atrazine (ATZ), a persistent organic pollutant, is one of the most used herbicides worldwide and Nigeria [14]. People are exposed to ATZ in the air [15] (Mair, 1978), water [16], and food. The atrazine effect in humans and animals primarily involves the endocrine system. Studies suggest that Atrazine is an endocrine disruptor that can cause hormone imbalance [17]. ATZ has induced obesity and insulin resistance in rats by impairing mitochondrial function [18].

Studies suggest that Atrazine is an endocrine disruptor that can cause hormone imbalance [17]. Atrazine can suppress the expression of functional glucose transporter in several organs leading to excessive blood glucose levels because glucose could not be picked up by the cells for metabolism, which could ultimately lead to diabetes [18]. Atrazine also causes mitochondrial dysfunction [19], which would lead to a decrease in substrate oxidation. The reduced oxidation, particularly fatty acids, results in lipid accumulation, including deposition of metabolically active lipid mediators such as diacylglycerols and ceramides [20]. Both diacylglycerol and ceramides (DAG and CER) have been shown to inhibit insulin signaling. DAG through protein kinase $c$ activation translocate to the plasma membrane and inhibits insulin receptor [21] and CER through inhibition of the protein kinase ART [22]. Therefore, DAG and CER accumulation are a plausible link between mitochondrial dysfunction and insulin resistance [20].

Virgin Coconut Oil (VCO) is unprocessed oil obtained from the mature and fresh kernel of the coconut fruit by mechanical or natural means, with or without mild heat [23]. VCO is rich in Lauric acid, an essential fatty acid that transforms into a compound - Monolaurin Acid that is believed to fight viral pathogens and protect the body from parasites [24]. VCO has been found to have hypoglycemic actions by enhancing insulin secretion and ameliorating oxidative stress-induced in type I Diabetes mellitus (DM) induced rats [25]. VCO was also found to ameliorate high-density lipoprotein levels in induced diabetic male rats [26]. As the regular determination of lipid levels and proper dieting is paramount in preventing the prevalence of certain risk factors (such as obesity) associated with DM [26], VCO's effects on high-density fats may be beneficial to the management of and prevention of diabetes.

This study aims to evaluate the fasting blood glucose level, serum insulin level, and GLUT4 levels in control; Atrazine administered, and diabetic groups.

\section{Materials and Methods}

\section{Experimental animals}

Adult male albino Wistar rats (180-200g body weight) were purchased and maintained at the animal house Unit of the Department of Physiology, Faculty of Basic Medical Sciences, University of Calabar. The animals were kept in a well-ventilated space to acclimatize for two weeks. The animals were fed with rat chow and allowed drinking water ad libitum. After the acclimatization period, the animals were weighed, their fasting blood glucose level was measured and reassigned before the commencement of the experimental treatment. The cages were cleared and kept clean throughout the experiment.

\section{Experimental design and treatment of animals}

We randomly assigned the thirty five (35) rats into two main groups named; the test group and recovery groups. The 35 rats in the test group were further assigned to five subgroups of seven rats each

Sub-Group (SG) 1 was normal control administered $10 \mathrm{ml} / \mathrm{kg}$ body weight of distilled water, SG 2 was administered $10 \mathrm{ml} / \mathrm{kg}$ of Virgin Coconut Oil (VCO), SG 3 was administered received $123 \mathrm{mg} / \mathrm{kg}$ (20\% of lethal dose) of Atrazine (ATZ), SG 4 was the diabetic control and were left untreated, and SG 5 was the diabetic group and was administered $10 \mathrm{ml} / \mathrm{kg}$ of VCO once daily by oral gavage. Administration in the test group was for 2 weeks, then the rats were sacrificed and blood collected for analysis. Group 4 and 5 were made diabetic after being assigned to their sub-groups.

Simultaneously in the first 2 weeks', thirtyfive rats for the recovery group were also subdivided into 5 sub-groups of 7 rats each: (SG) 1 was normal control and was administered $10 \mathrm{ml} / \mathrm{kg}$ body weight of distilled water, SG 2 was administered $10 \mathrm{ml} / \mathrm{kg}$ of Virgin Coconut Oil 
(VCO), SG 3, 4 and 5 were administered $123 \mathrm{mg} /$ $\mathrm{kg}$ of ATZ. After the first 2 weeks, the animals were then re-treated for recovery as follows: (SG) 1 was still administered $10 \mathrm{ml} / \mathrm{kg}$ body weight of distilled water, SG 2 was also still administered $10 \mathrm{ml} / \mathrm{kg}$ of Virgin Coconut Oil (VCO), 123mg/kg of ATZ administration also continued in SG 3, while SG 4 was administered $10 \mathrm{ml} / \mathrm{kg}$ of $\mathrm{VCO}$, and SG 5 was administered $10 \mathrm{ml} / \mathrm{kg}$ of distilled water. Recovery treatment also lasted for 2 weeks, after which the animals were sacrificed and blood collected for analysis.

Table 1. Experimental grouping and treatment TEST GRoup (2 WEEKS)

\begin{tabular}{|l|l|}
\hline GROUPS & TREATMENT \\
\hline Normal Control + H20 & $\begin{array}{l}10 \mathrm{ml} / \mathrm{kg} \text { of distilled water } \\
(\mathrm{H} 2 \mathrm{O})\end{array}$ \\
\hline Normal Control + VCO & $\begin{array}{l}10 \mathrm{ml} / \mathrm{kg} \text { of Virgin Coconut } \\
\text { Oil }(\mathrm{VCO})\end{array}$ \\
\hline Atrazine Treated & $\begin{array}{l}123 \mathrm{mg} / \mathrm{kg}(20 \% \text { of lethal } \\
\text { dose }) \text { of Atrazine }\end{array}$ \\
\hline Diabetic Control & $\begin{array}{l}10 \mathrm{ml} / \mathrm{kg} \text { of distilled water } \\
(\mathrm{H} 2 \mathrm{O})\end{array}$ \\
\hline Diabetic $+\mathrm{VCO}$ & $\begin{array}{l}10 \mathrm{ml} / \mathrm{kg} \text { of Virgin Coconut } \\
\text { Oil }(\mathrm{VCO})\end{array}$ \\
\hline
\end{tabular}

\section{ReCOVery Group (4 WEEKS)}

\begin{tabular}{|l|l|l|}
\hline GROUPS & $\begin{array}{l}\text { TREATMENT (1st } \\
\text { 2 weeks) }\end{array}$ & $\begin{array}{l}\text { TREATMENT } \\
\text { (2nd 2 weeks) }\end{array}$ \\
\hline $\begin{array}{l}\text { Normal Control } \\
+\mathrm{H} 20\end{array}$ & $\begin{array}{l}\text { 10ml/kg of } \\
\text { distilled water } \\
\text { (H2O) }\end{array}$ & $\begin{array}{l}\text { 10ml/kg of } \\
\text { distilled water } \\
(\mathrm{H} 2 \mathrm{O})\end{array}$ \\
\hline $\begin{array}{l}\text { Normal Control } \\
+ \text { VCO }\end{array}$ & $\begin{array}{l}\text { 10ml/kg of } \\
\text { Virgin Coconut } \\
\text { Oil (VCO) }\end{array}$ & $\begin{array}{l}10 \mathrm{ml} / \mathrm{kg} \text { of } \\
\text { Virgin Coconut } \\
\text { Oil (VCO) }\end{array}$ \\
\hline Atrazine Treated & $\begin{array}{l}123 \mathrm{mg} / \mathrm{kg}(20 \% \\
\text { of lethal dose) of } \\
\text { Atrazine }\end{array}$ & $\begin{array}{l}123 \mathrm{mg} / \mathrm{kg}(20 \% \\
\text { of lethal dose) of } \\
\text { Atrazine }\end{array}$ \\
\hline VCO after ATZ & $\begin{array}{l}\text { 123mg/kg (20\% } \\
\text { of lethal dose) of } \\
\text { Atrazine }\end{array}$ & $\begin{array}{l}10 \mathrm{ml} / \mathrm{kg} \text { of } \\
\text { Virgin Coconut } \\
\text { Oil (VCO) }\end{array}$ \\
\hline $\begin{array}{l}\text { Untreated after } \\
\text { ATZ }\end{array}$ & $\begin{array}{l}\text { 123mg/kg (20\% } \\
\text { of lethal dose) of } \\
\text { Atrazine }\end{array}$ & $\begin{array}{l}10 \mathrm{ml} / \mathrm{kg} \text { of } \\
\text { distilled water } \\
\text { (H2O) }\end{array}$ \\
\hline
\end{tabular}

Induction of Diabetes mellitus (DM): Diabetes was induced intraperitoneally using 150mg/ $\mathrm{kg}$ body weight of alloxan monohydrate once $[27,28]$. The diabetic state was observed from about 48 hours by the symptoms of polyuria and glucosuria. After 72 hours, DM was confirmed with a blood glucose level of $180-200 \mathrm{mg} / \mathrm{dL}$ and above [25] using a glucometer (ACCU-CHECK Active) and ACCU-CHECK compatible glucose test strips.
Preparation of Virgin Coconut Oil (VCO): Mature dried coconuts were purchased from the local market, and VCO was extracted using the modified wet extraction method [29]. The solid endosperm of mature coconut was crushed and made into a thick slurry. About $500 \mathrm{ml}$ of water was added to the slurry obtained and squeezed through a fine sieve to obtain coconut milk. The resultant coconut milk was left for about 18 hours to facilitate the gravitational separation of the emulsion. Demulsification produced layers of an aqueous phase (water) at the bottom, an oil phase in the middle layer, and an emulsion phase (cream) on top. The cream on top was removed, and the oil was scooped and warmed for about 5 minutes to remove moisture. The oil obtained was then filtered and stored at room temperature.

Determination of fasting blood glucose: Fasting blood glucose was determined using ACCU-Check blood glucose meter with compatible glucose test strips according to prescribed instructions by pricking the tail tip and dropping blood gently on the test strip. This was done before the induction of diabetes and 72 hours after induction; after which it was done weekly

\section{Estimation of serum insulin concentration:} The RayBio Rat Insulin ELISA kit (USA) was used for the determination of serum insulin concentration as used by Ghezzi et al. (2012) [30].

Assay Procedure: $100 \mu$ of each standard and sample were pipetted into appropriate wells and covered; they were incubated for 2.5 hours at room temperature with gentle shaking. (The Insulin present in a sample will bind to the wells by the immobilized antibody). The solution was discarded, and $300 \mu$ of the wash buffer was pipetted into each well and washed 4 times. After the last wash, the plate was inverted and blotted against clean paper towels. $100 \mu \mathrm{l}$ of biotinylated anti-Rat Insulin antibody was then added to each well and incubated for 1 hour at room temperature $\left(18-25^{\circ} \mathrm{C}\right)$ with gentle shaking. The solution was discarded, and wells washed as before to remove unbound biotinylated antibodies. $100 \mu 1$ of HRPconjugated Streptavidin solution was added to each well and incubated for 45 minutes at room temperature $\left(18-25^{\circ} \mathrm{C}\right)$ with gentle shaking. The solution was discarded and washed as before. $100 \mu \mathrm{l}$ of TMB One-Step Substrate Reagent was added to each well and incubated for 30minutes at room temperature in the dark with gentle shaking. The blue color developed in proportion to the amount of insulin bound. Lastly, $50 \mu l$ of Stop Solution was then added to each well which changes the color from blue to yellow, and the intensity of the color is measured at $450 \mathrm{~nm}$.

Ethical Approval: Full ethical approval (022PY30417) was given by the Faculty Animal Research Ethics Committee, Faculty of Basic Medical Sciences, University of Calabar, Calabar, 
Cross Rivers State. This was in accordance with the declaration of Helsinki (1964).

\section{Statistical analysis}

Statistical analysis was carried out using the windows SPSS package (SPSS 20.0). Data were analyzed using one-way ANOVA followed by Tukey's post hoc test. Data were expressed as mean + standard error of the mean (Mean \pm SEM). Results with values of $\mathrm{p}<0.05$ were considered significant.

\section{RESUlts}

Insulin levels $(\mu \mathrm{IU} / \mathrm{ml})$ in normal control, ATZ, and diabetic groups

The mean values for insulin are $14.94 \pm 0.31$, $16.18 \pm 0.16,11.82 \pm 0.31,10.68 \pm 0.41$, and $12.34 \pm 0.12$ for $\mathrm{NC}+\mathrm{H} 2 \mathrm{O}, \mathrm{NC}+\mathrm{VCO}, \mathrm{ATZ}$ treated, Diabetic control, and Diabetic + VCO groups, respectively. In figure 1, there was a significant $(\mathrm{p}<0.05)$ increase in insulin levels in the $\mathrm{NC}+\mathrm{VCO}$ group when compared to the $\mathrm{NC}+\mathrm{H} 2 \mathrm{O}$. ATZ significantly $(\mathrm{p}<0.05)$ decreased insulin levels when compared with the $\mathrm{NC}+$ $\mathrm{H} 2 \mathrm{O}$ and $\mathrm{NC}+\mathrm{VCO}$. Insulin level in the diabetic untreated group was significantly $(p<0.05)$ lower than $\mathrm{NC}+\mathrm{H} 2 \mathrm{O}, \mathrm{NC}+\mathrm{VCO}$ and ATZ administered groups. VCO administration significantly $(p<0.05)$ increased the insulin levels when compared with the diabetic untreated group but significantly $(\mathrm{p}<0.05)$ lower than the $\mathrm{NC}+\mathrm{H} 2 \mathrm{O}$ and $\mathrm{NC}+\mathrm{VCO}$ groups

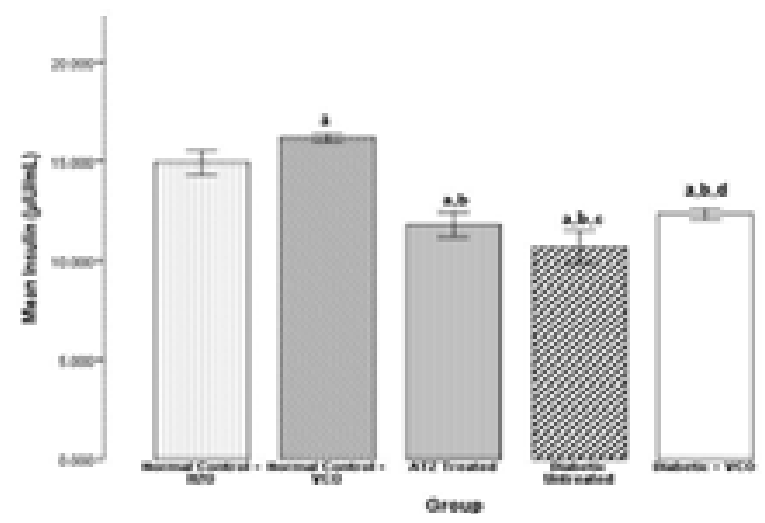

Fig 1. Comparison of Insulin levels in Control, ATZ and Diabetic groups.

Values are mean \pm SEM. $n=7$.

$a=p<0.05$ vs NC, $b=p<0.05$ vs NC + VCO, $c=$ $\mathrm{p}<0.05$ vs ATZ, $d=p<0.05$ vs Diabetic control

Insulin levels in normal control and ATZ recovery groups

A significant $(p<0.05)$ decrease was observed in mean insulin levels of the ATZ continued group (10.46 \pm 0.13$)$ when compared with the $\mathrm{NC}+$ $\mathrm{H} 2 \mathrm{O}(14.94 \pm 0.45)$ and NC + VCO (16.25 \pm 0.26$)$ groups. There was a significant $(p<0.05)$ increase with $\mathrm{VCO}$ administration in the $\mathrm{VCO}$ recovery group (11.65 \pm 0.16$)$ when compared to the ATZ continued group, but there was no significant $(p<0.05)$ difference between the insulin level in the $\mathrm{VCO}$ recovered and ATZ untreated group (11.13 \pm 0.12$)$ (Figure 2).

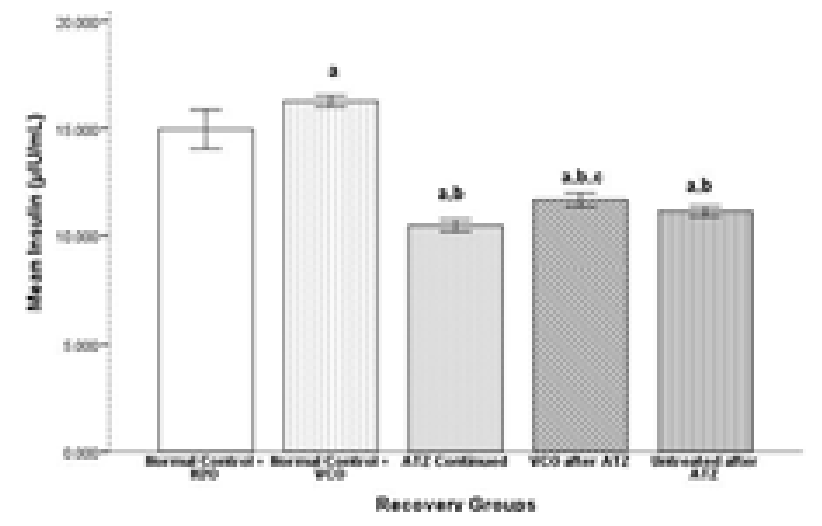

Fig 2. Comparison of Insulin levels in Control, ATZ Continued and Recovery Groups.

Values are mean \pm SEM. $n=7$.

$\mathrm{a}=\mathrm{p}<0.05$ vs $\mathrm{NC}, \mathrm{b}=\mathrm{p}<0.05$ vs $\mathrm{NC}+\mathrm{VCO}$, $\mathrm{c}=\mathrm{p}<0.05$ vs ATZ continued, $\mathrm{d}=\mathrm{p}<0.05 \mathrm{vs}$ $\mathrm{VCO}$ recovered

\section{GLUT4 levels (ng/ml) in normal control, ATZ and diabetic groups}

Figure 3 shows the mean levels of GLUT4 in the experimental groups, which are 97.32 \pm 0.51 , $142.86 \pm 0.99,78.64 \pm 0.35,74.82 \pm 0.37$, and $95.99 \pm 0.37$ for $\mathrm{NC}+\mathrm{H} 2 \mathrm{O}, \mathrm{NC}+\mathrm{VCO}, \mathrm{ATZ}$ treated, Diabetic control, and Diabetic +VCO groups, respectively. GLUT4 levels were found to be significantly $(p<0.05)$ higher in the $\mathrm{NC}+\mathrm{VCO}$ group than in the $\mathrm{NC}+\mathrm{H} 2 \mathrm{O}$ group. The GLUT4 level in the ATZ treated group was significantly $(\mathrm{p}<0.05)$ lower than that of the $\mathrm{NC}+\mathrm{VCO}$ and $\mathrm{NC}+\mathrm{H} 2 \mathrm{O}$ group. GLUT4 level in the diabetic untreated group was significantly $(p<0.05)$ lower than that of the ATZ-treated group, the $\mathrm{NC}+$ $\mathrm{VCO}$ group, and the $\mathrm{NC}+\mathrm{H} 2 \mathrm{O}$ group. In the diabetic VCO-treated group, their GLUT4 level was significantly $(p<0.05)$ higher than that of the diabetic untreated and ATZ-treated groups but significantly $(\mathrm{p}<0.05)$ lower than the $\mathrm{NC}+\mathrm{VCO}$ group and not significantly $(p<0.05)$ different from the $\mathrm{NC}+\mathrm{H} 2 \mathrm{O}$.

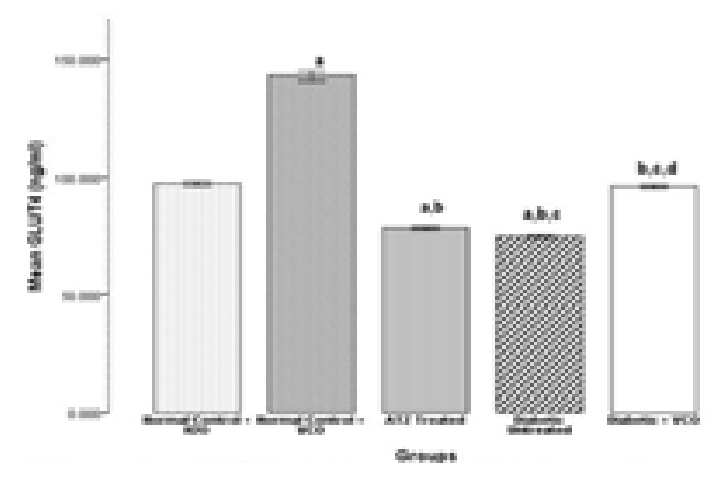

Fig 3. Comparison of Insulin levels in Control, ATZ and Diabetic groups. 
Values are mean \pm SEM. $\mathrm{n}=7$.

$\mathrm{a}=\mathrm{p}<0.05$ vs NC, $\mathrm{b}=\mathrm{p}<0.05$ vs NC $+\mathrm{VCO}, \mathrm{c}=$ $\mathrm{p}<0.05$ vs ATZ, $d=p<0.05$ vs Diabetic control

\section{GLUT4 levels in the normal control and ATZ} recovery groups

Figure 4 showed that the GLUT4 levels was significantly $(p<0.05)$ lower in ATZ continued group with mean values of $77.39 \pm 0.79$ when compared with the $\mathrm{NC}+\mathrm{H} 2 \mathrm{O}(97.06 \pm 0.57)$ and $\mathrm{NC}+\mathrm{VCO}(142.46 \pm 1.12)$ groups. The mean values of GLUT4 in the VCO recovered group $(111.66 \pm 0.76)$ was significantly $(p<0.05)$ higher than the $\mathrm{NC}+\mathrm{H} 2 \mathrm{O}$ group and ATZ continued group but significantly $(\mathrm{p}<0.05)$ lower than the NC + VCO group. In the untreated group $(102.53 \pm 0.53)$, GLUT4 level was significantly $(\mathrm{p}<0.05)$ lower than the $\mathrm{NC}+\mathrm{VCO}$ and $\mathrm{VCO}$ recovered group, but significantly $(\mathrm{p}<0.05)$ higher than ATZ continued group; though not significantly different from the $\mathrm{NC}+\mathrm{H} 2 \mathrm{O}$ group.

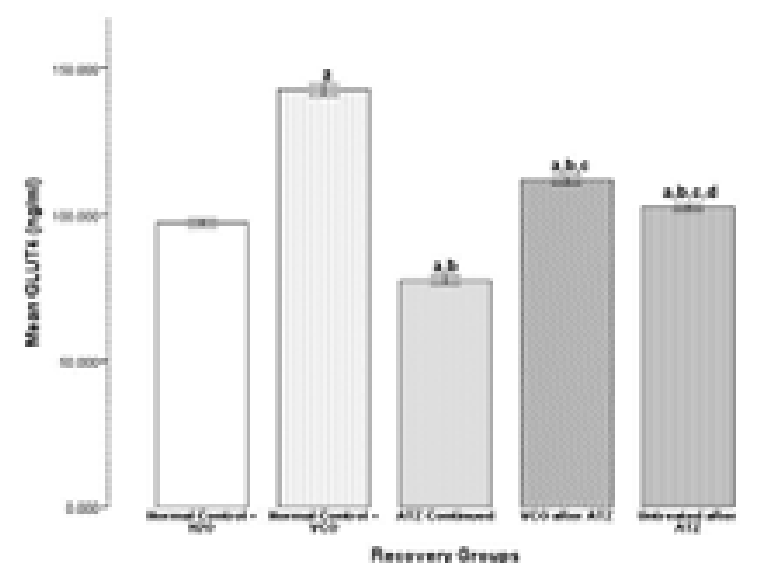

Fig 4. Comparison of Estradiol levels in Control, ATZ Continued and Recovery Groups.

Values are mean \pm SEM. $\mathrm{n}=7$.

$\mathrm{a}=\mathrm{p}<0.05$ vs $\mathrm{NC}, \mathrm{b}=\mathrm{p}<0.05$ vs $\mathrm{NC}+\mathrm{VCO}$, $\mathrm{c}=\mathrm{p}<0.05$ vs ATZ continued, $\mathrm{d}=\mathrm{p}<0.05$ vs VCO recovered

\section{Discussion}

The FBG (fasting blood glucose) concentration of the $\mathrm{NC}+\mathrm{H} 2 \mathrm{O}$ and $\mathrm{NC}+\mathrm{VCO}$ groups was not significantly different at the end of the experiment's first phase. This supports the report by Eleazu et al. (2019) [31], which showed no significant change in FBG concentration of the VCO group comparable to the $\mathrm{NC}+\mathrm{H} 2 \mathrm{O}$ group. The non-effect of $\mathrm{VCO}$ administration had on the FBG concentrations of the $\mathrm{NC}+\mathrm{VCO}$ concerning the $\mathrm{NC}+\mathrm{H} 2 \mathrm{O}$ group suggests that VCO did not negatively impact their blood glucose concentrations [31]. Triggering the production of reactive oxygen species (ROS), which in turn cause the destruction of the beta cells and eventually result in a condition of insulindependent diabetes, has been documented as the primary mechanism of action of alloxan- induced diabetes [32]. Thus, an alloxan-diabetic model is used to investigate diabetes arising from beta-cell destruction caused by ROS [25]. The primary marker of DM is hyperglycemia owing to a decrease in pancreatic insulin secretion or defective insulin action and insulin resistance by target cells [33]. Type 1 DM results from idiopathic or cellular-mediated autoimmune destruction of pancreatic $\beta$ - cells; patients thus depend totally on exogenous insulin [34]. Following alloxan injections, a significant increase in FBG of alloxan-induced diabetic animals in comparison to $\mathrm{NC}+\mathrm{H} 2 \mathrm{O}, \mathrm{NC}+\mathrm{VCO}$, and ATZ rats was noted. Similarly, several studies have documented a marked increase in blood glucose levels following alloxan induction $[25,31,35,36,37]$. It was observed that treatment of the diabetic group with $10 \mathrm{ml} / \mathrm{kg}$ of VCO for two weeks brought about a significant drop in fasting blood glucose levels. This further supports the hypoglycemic ability of VCO [38, 39]. Several other studies have also reported the hypoglycemic effect of VCO on alloxaninduced diabetic rats [25, 31, 37]. This beneficial potential of VCO on blood glucose level was attributed to its antioxidant ability [25]. Ngala and co-workers (2016) [40] observed that the administration of the coconut oil diet to diabetic mice significantly reduced blood glucose, which could be mediated through its antioxidant effect [40]. A study demonstrated that administering coconut oil prevented diabetes [41]. According to our report, a significant elevation of fasting blood glucose occurred in ATZ treated group comparable to $\mathrm{NC}+\mathrm{H} 2 \mathrm{O}$ and $\mathrm{NC}+\mathrm{VCO}$ groups but the level diminished concerning the diabetic untreated group. This probably showed that ATZ does not have a hyperglycemic effect on the fasting blood glucose for the 14 days, i.e., the fasting blood glucose level was still below $120 \mathrm{mg} / \mathrm{dl}$. This supports the report by Lim et al. (2009) [18], where FBG levels of rodents treated with ATZ and placed on a regular diet increased compared to the controls. Jestadi and co-workers (2014) [42] recorded a significant increment in FBG levels in diabetic untreated, and diabetic rats administered ATZ comparable to control rats; nevertheless, no significant difference in FBG concentration occurred comparing diabetic untreated and diabetic rats administered ATZ, showing that ATZ did not further aggravate the diabetic blood glucose during the two weeks' experimentation period. In the recovery group, the consistent elevation of the FBG concentration in the ATZ continued group was recorded; the fasting blood glucose level increased to a hyperglycemic level (125mg/dl-140mg/dl) but not up to the diabetic level (>140mg/dl) relative to this research. A significant reduction in FBG levels in the atrazine sub-group that was administered VCO compared with the other groups was observed. As a result of this, our report suggests that $\mathrm{VCO}$ has a mitigating effect on Atrazine induced hyperglycemia.

Insulin causes a decrease in blood glucose by enhancing amino acids, glucose, and fats take- 
up and storage after a meal; hence, a decline in the INL level in the plasma results in an increase in blood sugar. The primary marker of DM is hyperglycemia, which decreases pancreatic secretion of insulin or defective insulin action, i.e., insulin resistance by target cells [33]. Lauric oil, one of the components in VCO, has been documented to have insulinotropic potentials [25]. In the $\mathrm{NC}+\mathrm{VCO}$ groups, a significant increment in insulin levels was recorded concerning the $\mathrm{NC}+\mathrm{H} 2 \mathrm{O}$ group. The high insulin level seen in this group might be because of lauric acid in the VCO. A significant decline in insulin concentration occurred in ATZ and diabetic untreated group comparable to the control group. Reports of several researchers have shown that alloxan exerts a cytotoxic effect on pancreatic $\beta$ cells, resulting in Type 1 diabetes mellitus $[35,36]$. The mechanism of cytotoxic activity of alloxan on beta cells has to do with essential sulphydryl (-SH) group oxidation, glucokinase blockade, generation of toxic ROS, and cellular calcium homeostasis imbalance [36]. The resulting damage to $\beta$-cells, responsible for the reduced insulin secretion, results in a decrease in insulin release and the attendant hyperglycemia with metabolic and other associated diabetic complications. The fall in insulin level of the alloxan-induced diabetic animals observed in this study is similar to the reports by Iranloye et al. (2013) [36] and Udia et al. (2016) [43], who also observed a significant fall in serum insulin concentration of alloxan initiated diabetic rodents. Lack of insulin in $\mathrm{DM}$ is associated with diabetic complications, reversed or arrested when DM is appropriately managed with insulin injections or oral hypoglycaemic agents [44]. With VCO treatment in the Diabetic+VCO group, we observed a significant elevation in insulin concentration compared to diabetic untreated rats, though significantly less compared with the control groups, no significant change in comparison to ATZ treated groups. This supports the findings of Iranloye and colleagues (2013) [25] where they also recorded an increment in serum insulin in diabetic rodents treated with $10 \mathrm{ml} / \mathrm{kg}$ BW dose of VCO but a non-significant elevation of insulin levels in diabetic rodents administered $7.5 \mathrm{ml} /$ $\mathrm{kg}$ body weight was observed. They concluded that the ineffectiveness of $7.5 \mathrm{ml} / \mathrm{kg}$ body weight and effectiveness of $10 \mathrm{ml} / \mathrm{kg} \mathrm{BW}$ doses of VCO on serum insulin shows that the effect of VCO on glucose homeostasis is dose-dependent. Ngala et al. (2016) [40] reported on the effect of coconut oil alone and glibenclamide plus coconut oil alone in diabetic mice treatment. They observed that coconut oil has a synergistic effect on glibenclamide action. The hypoglycemic impact of the co-administration of glibenclamide and coconut oil was drastically higher than the impact of coconut alone. They reasoned that coconut oil could consequently incite insulin discharge which can potentiate the insulin release actuated by the drug glibenclamide or enhances insulin sensitivity. Though serum insulin level was significantly boosted in VCO treated rats compared to the diabetic untreated group, its level was reduced concerning $\mathrm{NC}+\mathrm{H} 2 \mathrm{O}$; we also infer that probably if VCO was used for a more extended period, the insulinotropic effects could be more evident. The study has revealed a significant $(p<0.001)$ increment in plasma insulin level in alloxan-administered rodents treated with leaf extracts of Rothmannia hispida comparable to control rodents and diabetic nontreated rodents [43]. They proposed that the increased insulin levels noted in their study resulted from the ability of the phytochemicals in Rothmannia hispida to stimulate insulin release, inhibit insulin breakdown, and/or regenerate pancreatic $\beta$-cells that were damaged by alloxan in the diabetic state. We also propose that the constituents or lauric acid present in VCO could have also stimulated insulin synthesis, release and inhibited insulin breakdown.

GLUT4 is a noteworthy transporter of glucose into the tissues and principal controller of the entire homeostasis of glucose [3]. Expression and translocation (to tissue surface) of GLUT4 receptors are mainly regulated by insulin secretion. GLUT4 plays a significant role in insulin-stimulated glucose uptake and utilization in skeletal muscles [45]. Insulin also increases the expression of GLUT4 in the target cells [46] and stimulates its translocation to the plasma membrane for the uptake of glucose [12]. In muscle, insulin facilitates the transportation of glucose by GLUT4, stimulates glycogen production and glycolysis.

Furthermore, it also enhances glucose uptake in the adipose tissue, and thus all maintain glucose metabolism. The results from the test group indicated a significant decrease of GLUT4 in diabetes-induced groups, compared to the control groups; this is similar to the investigation by Maria and co-workers (2013) [47], where they reported that the levels of GLUT4 reduced by up to $70 \%$ in diabetic mice compared with normal ones. Tsao et al. (1999) (48) also generated a type II diabetes experimental mouse model by a genetic interruption in one allele of GLUT4 in muscle and fat tissue, which prompts hyperglycemia and hyperinsulinemia; this demonstrated that a defect in GLUT4 might contribute to insulin resistance. The pesticide has been documented to reduce the expression of glucose transporters proteins in several organs, hypothesized to be the possible association between them and insulin disruption [49]. GLUT4 level in the ATZ-treated group was observed to be significantly lower than that of the control group. This reduction of GLUT4 in rats treated with ATZ could be due to Atrazine's oxidative properties because ATZ was found to suppress antioxidant enzyme defenses in rodents. Oxidation has been reported to induce carboxylation of the glucose transport channel of GLUT4, making them dysfunctional (8). From these results, it is reasonable to infer that Atrazine may, in the long-term, induce insulin resistance by causing dysfunction or a 
decrease in GLUT4 expression. This corresponds with the work of Lim et al. (2009) [18], where the insulin sensitivity index (ISI) was reported to be significantly lowered to an average of 4.35 for the ATZ treated group concerning 6.1 in controls. The decreased expression of GLUT4 levels and defect in GLUT4 trafficking may participate in the pathogenesis of hyperglycemia and are notably connected with insulin resistance [5]. Alloxaninduced diabetes and ATZ notably caused a decreased expression of GLUT4, which could be linked to the diabetic and hyperglycemic fasting blood glucose levels observed in the present research. The result revealed a significant increment in levels of GLUT4 in the NC+VCO group compared with the $\mathrm{NC}+\mathrm{H} 2 \mathrm{O}$ group; this increase might be because of VCO's antioxidative properties [50]. It was discovered that vanadium could increase GLUT4 expression in diabetic animals, but whether this occurs through direct interaction with the GLUT4 promoter or through a yet unknown pathway was not elucidated. VCO can also increase the GLUT4 expression in diabetic animals, and this may at least partially explain the glucoregulatory effects of VCO. The recovery group observed that the GLUT4 level in the VCO recovery group was significantly elevated concerning ATZ continued and untreated groups. Its GLUT4 level was elevated significantly than that of the $\mathrm{NC}+\mathrm{H} 2 \mathrm{O}$ group. It can thus be said that VCO can restore GLUT4 levels in rats exposed to ATZ. This increase in GLUT4 could be due to VCO antioxidative properties on tissues that express GLUT4. This antioxidative action may have allowed for the expression of the transporter, which had been rendered dysfunctional by ATZ and diabetes. The overall effect of this would be a decrease in blood glucose level, which corresponds with the work of Iranloye et al. (2013) [25] considerably diminished in diabetic rodents that received VCO (for four weeks) than diabetic untreated rats [25]. GLUT4 concentration in the untreated group was observed to be elevated than that of the ATZ-continued group. From this, it is reasonable to infer that withdrawal of ATZ from the animals led to a decrease in GLUT4 levels. Nevertheless, it is critical to highlight that the GLUT4 level of these rats was lesser compared with VCO-treated recovery rats.

\section{Conclusion}

Insulin is the dominant glucoregulatory hormone. The fasting state regulates the plasma glucose concentration primarily by restraining hepatic glucose production; higher concentrations, such as those found after meals, are required to stimulate glucose utilization [51]. GLUT4 is a significant mediator of glucose removal from the circulation and a key regulator of the whole-body glucose homeostasis [3]. Expression and translocation (to tissue surface) of GLUT4 receptors are mainly regulated by insulin secretion. This study has shown and confirmed the deleterious effects of atrazine and diabetes on glucose metabolism by reducing serum insulin and causing areduced expression of GLUT4. VCO restored GLUT4 levels but did not significantly restore the insulin to normal levels. Probably if used for a more extended period, the effects might be more pronounced.

\section{REFERENCES}

1. Navale A. M. and Paranjape A. N. Glucose transporters: physiological and pathological roles. Biophysical Reviews 2016; 8: 5-9.

2. Deng, D. and Yan, N. GLUT, SGLT, and SWEET: Structural and mechanistic investigations of the glucose transporters. Protein Science 2015;25: 546-558.

3. Huang S. and Czech M. The GLUT4 glucose transporter. Cell Metabolism 2007; 5:237252.

4. Sylow L., Kleinert M., Pehmøller C., Prats C., Chiu T.T., Klip A., Richter E.A., Jensen T.E. Akt and Rac1 signaling are jointly required for insulin-stimulated glucose uptake in skeletal muscle and downregulated in insulin resistance. Cell. Signal 2014;26:323-331. doi: 10.1016/j.cellsig.2013.11.007

5. Favaretto, F., Milan, G., Collin, G. B., Marshall, J. D., Stasi, F., Maffei P, Vettor R., Naggert, J. K. GLUT4 defects in adipose tissue are early signs of metabolic alterations in Alms1GT/GT, a mouse model for obesity and insulin resistance. PLoS ONE, 2014;9(10): e109540.

6. Leto D. and Saltiel, A. R. (). Regulation of glucose transport by insulin: traffic control of GLUT4. Nat Reviews Molecular Cell Biologi 2012; 13: 383-396.

7. Maria Z., Campolo A. R., Lacombe V. A. Diabetes Alters the xpression and translocation of the Insulin-Sensitive Glucose Transporters 4 and 8 in the Atria. PLoS ONE 2013; 10(12): e0146033.

8. Boden G., Homko C., Barrero, C. A.,Stein T. P., Chen X., Cheung P., Fecchio C., Koller S., Merali S. Excessive caloric intake acutely causes oxidative stress, GLUT4 carbonylation, and insulin resistance in healthy men. Sci Translational Medicine 2015;7:(304): 304re7.

9. Olatunbosun, S. Insulin Resistance: Practical essentials, pathophysiology, ethology 2017. Retrieved from https:// emedicine.medscape.com/article/122501overview.

10. Jiao, P., Ma, J., Feng, B., Zhang, H. et al. FFA-induced adipocyte inflammation and insulin resistance: Involvement of ER stress and IKK $\beta$ pathways. Obesity 2011; 19: 483491. 
11. Vinten J., Gliemann J., and Osterlind K. "Exchange of 3- O-methylglucose in isolated fat cells," Journal of Biological Chemistry, 1976; 251(3), pp. 794-800.

12. Shepherd P. R., Gnudi L., Tozzo E., Yang, H. Leach F., and Kahn B. B. Adipose cell hyperplasia and enhanced glucose disposal in transgenic mice overexpressing GLUT4 selectively in adipose tissue. Journal of Biological Chemistry, 1993;268(30), pp. 22243-22246

13. Tsao T. S., A. E. Stenbit, J. Li (). "Musclespecific transgenic complementation of GLUT4-deficient mice: effects on glucose but not lipid metabolism," Journal of Clinical Investigation, 1997; 100(3): 671-677.

14. Chikoye, D., Udensi, E. U. and Fontem, A. L.. Performance of a new formulation of ATZ for weed control in maize in Nigeria. Food, Agriculture and Environment 2006; 14590263, 4(3\&4), p 114-117

15. Mair D. C., Yoo, J. Y., Baker, B. E. Residues of ATZ and N-dealkylated ATZ in

water from five agricultural watersheds in Quebec. Archives of environmental

contamination and toxicology 1978; 7:221225.

16. Funari, E. Preliminary report on the ATZ and molinate water supply contamination in Italy.Chemosphere 1989; 18:2339-2343.

17. Kucka M., Pogrmic-Majkic K., Fa S., Stojilkovic S. S. (). Atrazine acts as an endocrine disrupter by inhibiting cAMPspecific phosphodiesterase, Toxicol Appl Pharmacol. 2012; 15; 265(1):19-26.

18. Lim S., Ahn S. Y., Song I. C., Chung M. H., Jang H. C., Park K. S., Lee K. U., Pak Y. K., Lee H. K. Chronic exposure to the herbicide, Atrazine, causes mitochondrial dysfunction and insulin resistance. PLoS One 2009;4(4): e5186.

19. 19. Olsen H., Enan E. and Matsumura F. Regulation of glucose transport in the NIH 3T3 L1 preadipocyte cell line by TCDD. Environmental Health Perspectives 1994, 102(5): 454-458.

20. Magdalene K. and Nigel T. Mitochondrial dysfunction and insulin resistance. Endocrine connect 2015, 4(1):1-15.

21. Samuel V. T., Petersen, K. F. and Shulman, G. I. Lipid-induced insulin resistance: unravelling the mechanism. Lancet, 2010; 375: $2267-2277$.

22. Bruce C., Risis S., Babb, J., Yang C., Kowalski G. , Selathurai A., Lee-Young R. S., Weir J. M., Yoshioka K. and Takuwa Y. Overexpression of sphingosine kinase
1 prevents ceramide accumulation and ameliorates muscle insulin resistance in high-fat diet-fed mice Diabetes. Diabetes 2012; 61: 3148-3155.

23. Villarino, B., Dy, L., and Lizada, C. Descriptive sensory evaluation of virgin coconut oil and refined, bleached and deodorized coconut oil .LWT-Food Science and Technology 2007; 40:193-199

24. Bergsson, G., Arnfinnsson, J., Karlsson, S., Steingrimsson, $\mathrm{O}$. and Chormar, $\mathrm{H}$. In vitro inactivation of Chlamydia tracomatis by fatty acids and monoglycerides. Antimicrorbial Agents and Chemotherapy 1998; 42(9):42290.

25. Iranloye B., Oludare G. and Olubiyi M. Antidiabetic and antioxidant effects of virgin coconut oil in alloxan induced diabetic male Sprague Dawley rats. Journal of Diabetes Mellitus 2013; 3: 221-226.

26. Akinnuga A. M., Jeje S. O., Bamidele O., Amaku E. E., Otogo F. O., and Sunday V. E. Virgin Coconut Oil: Remedial Effects on Renal Dysfunction in Diabetic Rats. Physiology Journal, 2014; 495926, 5 pages http://dx.doi.org/10.1155/2014/495926

27. Katsumata K., Katsumata Y., Ozawa T. Potentiating effects of combined usage of three sulfonylurea drugs on the occurrence of alloxan diabetes in rats. Hormone Metab. Res. 1993; 25: 125-126

28. Etuk, E.U. Animals models for studying diabetes mellitus. Agric. Biol. J. N. Am. 2010, 1(2): 130-134.

29. Nevin K. G. and Rajamohan T. Virgin coconut oil supplemented diet increases the antioxidant status in rats. Food Chemistry, 2006; 99(2):260-266.

30. Ghezzi, A. C., Cambri, L. T., Botezelli, J. D., Ribeiro, C., Dalia, R. A., \& de Mello, M. A. Metabolic syndrome markers in wistar rats of different ages.Diabetology\& metabolic syndrome 2012; 4(1):16.doi:10.1186/17585996-4-16

31. Eleazu C., Egedigwe-Ekeleme C, Famurewa A, Mohamed M, Akunna G, David E, Nwofe B, Chukwu F. Modulation of the lipid profile, hepatic and renal antioxidant activities, and markers of hepatic and renal dysfunctions in alloxan-induced diabetic rats by virgin coconut oil. Endocr Metab Immune DisordDrug Targets 2019, 19;1-8. doi: 10.2174/18 71530319666190119101058

32. Lenzen S. The mechanisms of alloxanand streptozotocin-induced diabetes. Diabetologia 2008; 51, 216-226. http:// dx.doi.org/10.1007/s00125-007-0886-7 
33. Motala A.A., Omar M.A., Pirie F.J. Type 1 diabetes in Africa: Epidemiology and pathogenesis. Diabetes Int. 2000; 10 (2): 4447

34. Wild S., Roglic G., Green A., Sicree R. and King, H. Global prevalence of diabetes. Diabetes Care 2004; 27(5), 1047-1053.

35. Lenzen S., Tiedge M., Jorns A., Munday R. (). Alloxan derivatives as a tool for the elucidation of the mechanism of the diabetogenic action of alloxan. In E. Sharper (Ed.), Lessons from animal diabetes 1996; 113 - 122. http:// dx.doi.org/ 10.1007/978-1-4612-4112-6_8.

36. Szkudelski T. The mechanism of alloxan and streptozotocin action in B cells of the rat pancreas. Physiology Res 2001.; 50 (6): 537546.

37. Maidin N. H., Norhayati Ahmad . Protective and Antidiabetic Effects of Virgin Coconut Oil (VCO) On Blood Glucose Concentrations in Alloxan Induced Diabetic Rats. Int $\mathrm{J}$ Pharm Pharm Sci, 2015; 7(10), 57-60.

38. Garfinkel M., Lee S., Opara E. and Akwari, O. C. Insulunotropic potency of lauric acid.A menabolic rationale for medium chain fatty acids (MCF) in TPN -formulation. Journal of surgical research 1992; 52: 328-333.

39. Sadikot, S.M. Coconut for health nutrition. Jakarta, APCC 2005,

40. Ngala R., Isaac A., Samuel A. and Enoch O. Effect of dietary vegetable oil consumption on blood glucose levels, lipid profile and weight in diabetic mice: an experimental case-control study, BMC Nutrition 2016; 2:28 DOI 10.1186/s40795-016-0053.

41. Houssay B and Martinez C. Experimental diabetes and diet.Sci. 1947;105(2734):5489.

42. Jestadi D., Phaniendra A., Babji U. Effect of short term exposure of Atrazine on the liver and kidney of normal and diabetic rats.
Journal of Toxicology, 2014 (6).

43. Udia P. M., Takem L. P., Ufot U. F., Antai A. B., Owu D. U. Insulin and alpha amylase levels in alloxan-induced diabetic rats and the effect of Rothmannia hispida(K. Schum) Fagerl leaf extract. The Journal of Phytopharmacology 2016;5(1):1-5.

44. Holmboe E.S. Antihyperglycaemic therapy for Type 2 diabetes: Clinical application. J Am Med Ass. 2002; 87: 373 -376.

45. Coster, A. C., Roland, G., David J. E. Insulin stimulates the entry of GLUT4 into the endosomal recycling pathway by a quantal mechanism. Traffic 2004; 10:763-771.

46. Olson A. L. and Knight J. B. "Regulation of GLUT4 expression in vivo and in vitro," Frontiers in Bioscience 2003;8: 401-409

47. Maria, Z., Campolo, A. R. \& Lacombe, V. A. Diabetes Alters the expression and translocation of the Insulin-Sensitive Glucose Transporters 4 and 8 in the Atria. PLoS ONE 2013; 10(12), e0146033

48. Tsao T. S., Stenbit, A. E., Factor, S. M., Chen, W., Rossetti, L., and Charron M. J. Prevention of insulin resistance and diabetes in mice heterozygous for GLUT4 ablation by transgenic complementation of GLUT4 in skeletal muscle. Diabetes 1999; 48: 775782 .

49. Liu S. and Mauvais-Jarvis F. "Rapid, nongenomic estrogen actions protect pancreatic islet survival," Islets 2009; 1( 3):273-275.

50. Yeap S. K., Beh B. K., Ali N. M. Anti-stress and antioxidant effects of virgin coconut oil in vivo. Experimental and Therapeutic Medicine 2015; 9(1): 39-42.

51. Rizza R. A., Mandarino L. and Gerich J. E. (). Dose-response characteristics for the effects of insulin on production and utilization of glucose in man. American Journal of Physiology 1981; 240:630 -9. 